\title{
PENGENDALIAN PROSES VARIABILITAS MULTIVARIAT MELALUI VEKTOR RAGAM (STUDI KASUS : IPK DAN LAMA STUDI LULUSAN MATEMATIKA UNIVERSITAS ANDALAS)
}

\author{
SILVIA, MAIYASTRI, FERRA YANUAR \\ Program Studi Matematika, \\ Fakultas Matematika dan Ilmu Pengetahuan Alam, Universitas Andalas, \\ Kampus UNAND Limau Manis Padang, Indonesia, \\ Silvia.1990@yahoo.co.id
}

\begin{abstract}
Abstrak. Pengendalian proses variabilitas melibatkan lebih dari dua karakteristik mutu proses yang disebut proses multivariat. Penelitian ini bertujuan melakukan penerapan vektor ragam dalam pengendalian proses variabilitas multivariat. Penelitian ini membahas tentang pengendalian proses variabilitas untuk 2 variabel yaitu: $\operatorname{IPK}\left(X_{1}\right)$ dan lama studi $\left(X_{2}\right)$ lulusan jurusan Matematika Universitas Andalas dengan vektor ragam yang dinyatakan dalam bentuk $\operatorname{Tr}\left(S^{2}\right)$
\end{abstract}

Kata Kunci: Multivariat, Vektor Ragam, Batas-Batas Kendali, Bagan Kendali

\section{Pendahuluan}

Perguruan tinggi mempunyai banyak hal yang dapat menjadi pedoman untuk dapat melihat prestasi mahasiswa. Salah satunya penilaian kualitas dari Perguruan Tinggi adalah nilai IPK dan lama studi para lulusan. Mahasiswa yang memiliki nilai IPK yang tinggi serta lama studi lulusan paling cepat merupakan Mahasiswa yang memiliki prestasi yang baik. Untuk mengetahui IPK dan lama studi lulusan di perguruan tinggi selama beberapa waktu digunakan bagan kendali mutu. Bagan kendali merupakan alat pengontrol dari suatu proses. Pada mutu pembelajaran di perguruan tinggi, digunakan bagan kendali mutu untuk melihat bagaimana hasil pembelajaran yang ditunjukkan IPK dan lama studi dari tahun ke tahun. Salah satu proses yang dilihat adalah proses variabilitas/keragaman. Pada bagan kendali univariat digunakan bagan kendali $R$ dan $s$ sedangkan untuk kasus multivariat pengendalian proses variabilitas menggunakan bagan kendali $|S|[4]$.

Pada skripsi ini yang digunakan bagan kendali multivariat untuk melihat proses variabilitas beberapa peubah. Pengendalian proses multivariat merupakan salah satu bagian yang cepat berkembang karena ada banyak situasi nyata yang melibatkan lebih dari dua karakteristik kualitas proses yang saling berhubungan. Pengendalian proses multivariat ini selanjutnya dikenal sebagai Multivariate Statistic Process Control (MSPC) [1]. Pada pengendalian proses multivariat ini juga dapat dilakukan dengan menggunakan peta kendali Shewhart yang pada umumnya digunakan untuk pengendalian proses rata-rata (mean process) dan proses keragaman. 
Dengan demikian maka pada skripsi ini akan diterapkan tentang pembentukan bagan kendali dari proses variabilitas dengan statistik vektor. Adapun Tujuan penelitian ini adalah melakukan penerapan vektor ragam dalam pengendalian proses variabilitas multivariat pada data IPK dan lama studi lulusan Mahasiswa Jurusan Matematika Universitas Andalas.

\section{Matriks Ragam Peragam}

Misalkan $X=\left[\begin{array}{cccc}x_{11} & x_{12} & \ldots & x_{1 p} \\ x_{21} & x_{22} & \ldots & x_{2 p} \\ \ldots & \ldots & \ldots & \ldots \\ x_{n 1} & x_{n 2} & \ldots & x_{n p}\end{array}\right]$ merupakan data matriks berukuran $n \times p$ yang merupakan matriks data $p$-peubah dengan $n$ buah sampel [2]. Dinotasikan $x_{1}=$ $\left[\begin{array}{c}x_{11} \\ \ldots \\ x_{1 p}\end{array}\right], \quad x_{2}=\left[\begin{array}{c}x_{21} \\ \ldots \\ x_{2 p}\end{array}\right], \ldots, x_{n}=\left[\begin{array}{c}x_{n 1} \\ \ldots \\ x_{n p}\end{array}\right]$ adalah vektor sampel acak berukuran $\mathrm{p}$ maka vektor rata-rata sampel dapat dinotasikan sebagai berikut:

$$
\bar{X}=\left[\begin{array}{c}
\bar{X}_{1} \\
\cdots \\
\bar{X}_{p}
\end{array}\right]
$$

Keragaman data multivariat di tampilkan dalam matriks ragam peragam yang berisi semua ragam peubah dan peragam antar peubah. Matriks tersebut dilambangkan $S$ di tulis sebagai berikut:

$$
S=\left[\begin{array}{llll}
s_{11} & s_{12} & \ldots & s_{1 p} \\
s_{21} & s_{22} & \ldots & s_{2 p} \\
\ldots & \ldots & \ldots & \ldots \\
s_{p 1} & s_{p 2} & \ldots & s_{p p}
\end{array}\right]
$$

dimana,

$$
s_{i j}=\frac{1}{n-1} \sum_{k=1}^{n}\left(x_{k i}-\bar{x}_{i}\right)\left(x_{k j}-\bar{x}_{j}\right) ; i=1,2, \ldots, p ; j=1,2, \ldots, p .
$$

karena $s_{i j}=s_{j i}$, maka $S$ merupakan matriks yang simetrik.

\section{Ukuran Keragaman}

Pada pengendalian proses variabilitas vektor ragam, ukuran keragaman dilambangkan dengan $\operatorname{Tr}\left(S^{2}\right)$ [5]. Dengan cara yang berbeda ukuran keragaman juga dapat ditentukan dengan turunan rumus sebagai berikut

$$
\begin{aligned}
& \operatorname{Tr}\left(S^{2}\right)=\operatorname{Tr}(S S)=\operatorname{Tr}\left(\left(\begin{array}{cccc}
s_{11} & s_{12} & \ldots & s_{1 p} \\
s_{21} & s_{22} & \ldots & s_{2 p} \\
\ldots & \ldots & \ldots & \ldots \\
s_{p 1} & s_{p 2} & \ldots & s_{p p}
\end{array}\right)\left(\begin{array}{cccc}
s_{11} & s_{12} & \ldots & s_{1 p} \\
s_{21} & s_{22} & \ldots & s_{2 p} \\
\ldots & \ldots & \ldots & \ldots \\
s_{p 1} & s_{p 2} & \ldots & s_{p p}
\end{array}\right)\right) \\
& =s_{11}^{2}+s_{21}^{2}+\ldots+s_{p 1}^{2}+s_{12}^{2}+s_{22}^{2}+\ldots+s_{p 2}^{2}+\ldots+s_{1 p}^{2}+s_{2 p}^{2}+\ldots+s_{p p}^{2}
\end{aligned}
$$


Dengan demikian, vektor ragam sampel $\operatorname{Tr}\left(S^{2}\right)=\operatorname{vec}(S)^{t}(\operatorname{vec}(S))$ merupakan jumlah elemen-elemen diagonal dari matriks $S^{2}$, yaitu

$$
\operatorname{Tr}\left(S^{2}\right)=\Sigma_{i=1}^{p} \Sigma_{j=1}^{p} s_{i j}^{2}
$$

\section{Batas -Batas Kendali Matriks Ragam Peragam Sampel}

\section{Kasus I.}

Misalkan suatu pengamatan ke $1,2, \ldots, m$ memiliki banyak sampel yang sama dengan $n_{1}=n_{2}=n_{3}=\ldots=n_{m}=n_{0}$. Statistik $\operatorname{Tr}\left(S^{2}\right)$ yang akan digunakan pada pengendalian proses variabilitas vektor ragam berdasarkan [5] adalah sebagai berikut:

$$
\operatorname{Tr}\left(S^{2}\right) \sim N\left(\operatorname{Tr}\left(\Sigma^{2}\right), \frac{8}{n-1} \operatorname{Tr}\left(\Sigma^{4}\right)\right)
$$

adapun mean dari $\operatorname{Tr}\left(S^{2}\right)$ adalah $\operatorname{Tr}\left(\Sigma^{2}\right)$ dan ragam dari $\operatorname{Tr}\left(S^{2}\right)$ adalah $\frac{8}{n-1} \operatorname{Tr}\left(\Sigma^{4}\right)$. Adapun nilai taksiran adalah :

$$
E\left[\operatorname{Tr}\left(\bar{S}_{g a b .}^{2}\right)\right]=\left(1+\frac{2}{\left(m\left(n_{0}-1\right)\right)}\right)^{-1} \operatorname{Tr}\left(\bar{S}_{g a b .}^{2}\right)
$$

dengan $\operatorname{Tr}\left(\bar{S}_{g a b .}^{2}\right)$ merupakan nilai ukuran keragaman setelah diperoleh matriks ragam peragam gabungan atau rata-rata dari matriks ragam peragam $\bar{S}_{g a b}$.

$$
\bar{S}_{g a b}=\frac{\sum_{i=1}^{m}\left(n_{i}-1\right) S_{i}}{\left(\sum_{i=1}^{m}\left(n_{i}-1\right)\right)}=\frac{1}{n-m} \sum_{i=1}^{m}\left(n_{i}-1\right) S_{i}
$$

dimana $n=\sum_{i=1}^{m} n_{i}$ dan $S_{i}$ merupakan matriks ragam peragam pada pengamatan/subgrup ke- $i$ dengan $i=1,2, \ldots, m$.

$$
\operatorname{var}\left\{\operatorname{Tr}\left(\bar{S}_{g a b .}^{2}\right\}=\frac{8}{n_{0}-1}\left(1+\frac{12}{m\left(n_{0}-1\right)}+\frac{12}{m\left(n_{0}-1\right)}\right)^{-1} \operatorname{Tr}\left(\bar{S}_{g a b .}\right)^{4}\right.
$$

Batas-batas kendali pada bagan kendali $\operatorname{Tr}\left(S^{2}\right)$ yang didefinisikan sebagai berikut:

$$
\begin{aligned}
B K A & =1+\left(\frac{2}{m\left(n_{0}-1\right)}\right) \operatorname{Tr}\left(\bar{S}_{g a b}^{2}\right)+3 \sqrt{\left(1+\frac{12}{m\left(n_{0}-1\right)}+\frac{12}{m\left(n_{0}-1\right)}\right)^{-1} \operatorname{Tr}\left(\bar{S}_{g a b}^{4}\right)} \\
G T & =\left(\frac{2}{m\left(n_{0}-1\right)}\right) \operatorname{Tr}\left(\bar{S}_{g a b}^{2}\right) \\
B K B & =1+\left(\frac{2}{m\left(n_{0}-1\right)}\right) \operatorname{Tr}\left(\bar{S}_{g a b}^{2}\right)-3 \sqrt{\left(1+\frac{12}{m\left(n_{0}-1\right)}+\frac{12}{m\left(n_{0}-1\right)}\right)^{-1} \operatorname{Tr}\left(\bar{S}_{g a b}^{4}\right)}
\end{aligned}
$$

Kasus II.

Misalkan suatu pengamatan ke $1,2, \ldots, m$ memiliki banyak sampel yang berbeda dengan $n_{1} \neq n_{2} \neq n_{3} \ldots \doteq n_{m}$. Statistik $\operatorname{Tr}\left(S^{2}\right)$ yang akan digunakan pada pengendalian proses variabilitas vektor ragam berdasarkan [5] adalah sebagai berikut:

$$
\operatorname{Tr}\left(S^{2}\right) \sim N\left(\operatorname{Tr}\left(\Sigma^{2}\right), \frac{8}{n-1} \operatorname{Tr}\left(\Sigma^{4}\right) .\right.
$$


Adapun nilai taksiran adalah :

$$
\begin{aligned}
E\left[\operatorname{Tr}\left(\bar{S}_{g a b}^{2}\right]\right. & =\left(1+\frac{2}{n-m}^{-1}\right) \operatorname{Tr}\left(\bar{S}_{g a b}^{2}\right) \\
\operatorname{var} \operatorname{Tr}\left(\bar{S}_{g a b}^{2}\right) & =\frac{8}{n-1}\left(1+\frac{12}{n-m}+\frac{12}{n-m}^{2}\right)^{-1} \operatorname{Tr}\left(\bar{S}_{g a b}^{4}\right)
\end{aligned}
$$

Batas-batas kendali pada bagan kendali $\operatorname{Tr}\left(S^{2}\right)$ yang didefinisikan sebagai berikut:

$$
\begin{aligned}
B K A & =\left(1+\frac{2}{n-m}\right) \operatorname{Tr}\left(\bar{S}_{\text {gab }}^{2}\right)+3 \sqrt{\frac{8}{n-1}\left(1+\frac{12}{n-m}+\frac{12}{n-m}^{2}\right)^{-1} \operatorname{Tr}\left(\bar{S}_{\text {gab }}^{4}\right)} \\
G T & =\left(1+\frac{2}{n-m}\right) \operatorname{Tr}\left(\bar{S}_{\text {gab }}^{2}\right) \\
B K B & =\left(1+\frac{2}{n-m}\right) \operatorname{Tr}\left(\bar{S}_{\text {gab }}^{2}\right)-3 \sqrt{\frac{8}{n-1}\left(1+\frac{12}{n-m}+\frac{12}{n-m}^{2}\right)^{-1} \operatorname{Tr}\left(\bar{S}_{\text {gab }}^{4}\right)}
\end{aligned}
$$

\section{Metodologi Penelitian}

\subsection{Data}

Pengambilan data untuk penelitian ini dilakukan di Jurusan Matematika Universitas. Data yang digunakan adalah nilai IPK dan lama sudi lulusan Matematika Universitas Andalas. Pengamatan atau Subgrup dalam penelitian ini adalah tahun wisuda mahasiswa. Terdapat 6 pengamatan, mulai dari tahun 2008 sampai dengan tahun 2013. Untuk masing-masing pengamatan terdapat lulusan matematika sebagai sampel dan untuk setiap sampel dicatat data berupa IPK $\left(X_{1}\right)$ dan lama studi $\left(X_{2}\right)$ dalam bulan).

\section{Analisis dan Pembahasan}

Dalam penelitian ini akan dijelaskan deskripsi IPK dan lama studi lulusan Mahasiswa Jurusan Matematika Universitas Andalas. Deskripsi data tersebut terlihat dalam sebaran data dan kehadiran pencilan. Pada data IPK dan lama studi lulusan dari ke-6 pengamatan dapat disajikan dalam diagaram kotak garis pada Gambar 1 dan Gambar 2.

Dari diagram kotak garis pada data IPK masing-masing pengamatan data menyebar simetrik dengan nilai rata-rata sebesar 3.00 dan pada gambar tersebut ada 4 pengamatan yang memiliki pencilan sedangkan, pada data IPK memiliki sebaran data yang simetrik dan pada data lama studi lulusan memiliki sebaran data yang tidak simetrik sehingga peneliti dapat melakukan suatu proses pengendalian dengan menggunakan pengendalian proses variabilitas multivariat melalui vektor ragam. Pada proses tersebut akan dilakukan pembuatan bagan kendali vektor ragam dengan melalui dua fase, yaitu fase data pendahuluan dan fase monitoring.

(1) Fase Pendahuluan

Pada fase ini digunakan 3 pengamatan/subgrup yaitu tahun 2008-2010, dan 


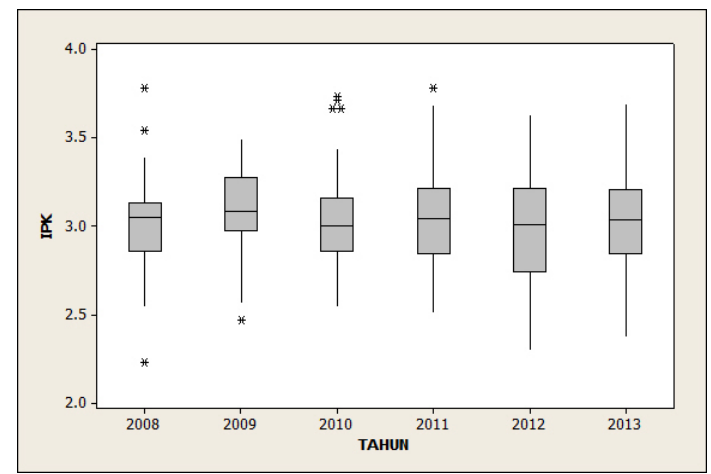

Gambar 1. Grafik Kotak Garis data IPK

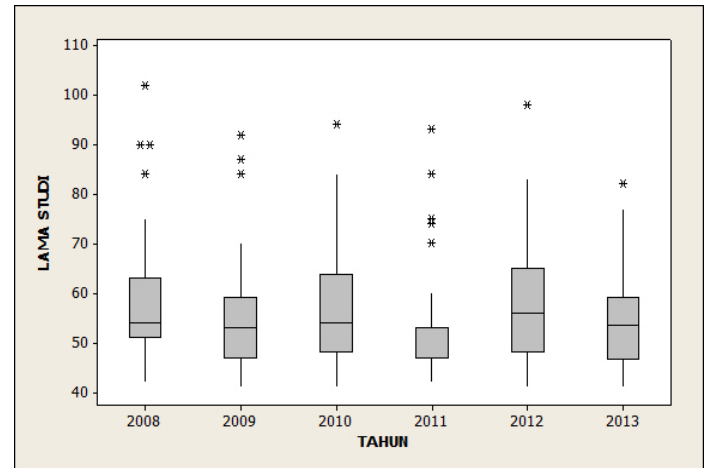

Gambar 2. Grafik Kotak Garis data Lama Studi

pengamatan lainnya akan digunakan untuk fase monitoring yaitu tahun 20112013. Pengolahan data masing-masing subgrup dengan menggunakan minitab 16 dan Microsoft Excel, maka didapatkan matriks ragam sampel dan ukuran keragaman untuk tiap pengamatan fase ini pada tabel berikut.

Tabel 1. Matriks Ragam Sampel dan Ukuran Keragaman Tahun 2008 -2010

\begin{tabular}{ccc}
\hline Tahun & Matriks Ragam Peragam Sampel & $\operatorname{Ts}\left(S^{2}\right)$ \\
\hline 2008 & {$\left[\begin{array}{cc}0.06 & -1.88 \\
-1.88 & 114.74\end{array}\right]$} & 13172.34 \\
2009 & {$\left[\begin{array}{rr}0.05 & -2.01 \\
-2.01 & 116.91\end{array}\right]$} & 13676.90 \\
2010 & {$\left[\begin{array}{rr}0.07 & -2.05 \\
-2.05 & 116.17\end{array}\right]$} & 13503.68 \\
\hline Rata-rata & {$\left[\begin{array}{cc}0.06 & -1.97 \\
-1.97 & 115.80\end{array}\right]$} & $\operatorname{Tr}\left(\bar{S}_{\text {gab. }}^{2}\right)=13417.41$ \\
\hline
\end{tabular}

Berdasarkan statistik pengendalian multivariat pada Tabel 1 yang diperoleh batas kendali melalui vektor ragam yang diaplikasikan pada data sekunder yang 


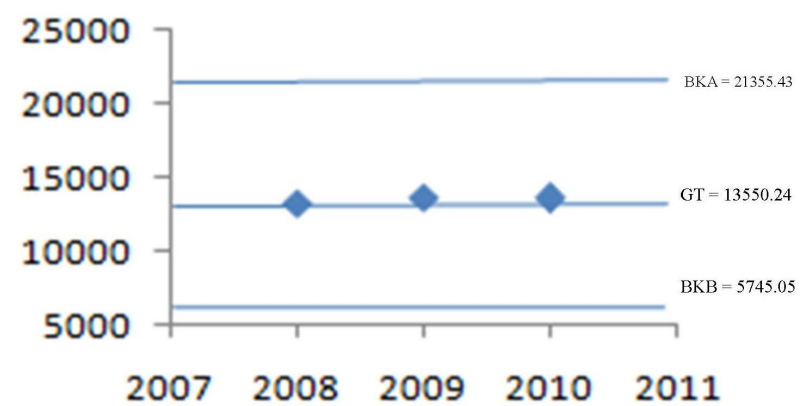

Gambar 3. Bagan Kendali Vektor Ragam Fase I

diambil berdasarkan IPK dan lama studi lulusan Mahasiswa Jurusan Matematika Universitas. Dari nilai peubah $p=2$, banyak pengamatan $m=3$, banyak sampel setiap pengamatan $n_{1}=79, n_{2}=51$ dan $n_{3}=76$, sehingga didapatkan nilai batas kendali atas sebesar 21355.43 , garis tengah sebesar 13550.24, dan batas kendali bawah sebesar 5745.05. Setelah nilai BKA, GT serta BKB didapatkan, maka bagan kendali pada fase I ini digambarkam pada Gambar 1.

Dari Gambar 3 bagan kendali diatas, terlihat bahwa semua pengamatan berada di dalam batas kendali. Dikarenakan pada fase I merupakan fase pengontrol untuk seluruh pengamatan, maka proses dapat dilanjutkan pada fase II.

(2) Fase Monitoring

Pada fase II, terlebih dahulu perlu diketahui matriks ragam peragamnya, pengamatan yang digunakan berbeda dengan fase I. Fase ini digunakan 3 pengamatan yakni pengamatan dengan peubah IPK dan lama studi pada tahun 2011-2013. Maka matriks ragam peragam sampel dapat dilihat pada Tabel 2.

Tabel 2. Matriks Ragam Sampel dan Ukuran Keragaman Tahun 2011-2013

\begin{tabular}{ccc}
\hline Tahun & Matriks Ragam Peragam Sampel & $\operatorname{Ts}\left(S^{2}\right)$ \\
\hline 2011 & {$\left[\begin{array}{cc}0.08 & -0.89 \\
-0.89 & 69.78\end{array}\right]$} & 4871.13 \\
2012 & {$\left[\begin{array}{cc}0.09 & -3.02 \\
-3.02 & 147.06\end{array}\right]$} & 21644.23 \\
2013 & {$\left[\begin{array}{cc}0.08 & -2.70 \\
-2.70 & 118.61\end{array}\right]$} & 14082.92 \\
\hline Rata-rata & {$\left[\begin{array}{cc}0.08 & -1.99 \\
-1.99 & 106.13\end{array}\right]$} & $\operatorname{Tr}\left(\bar{S}_{\text {gab. }}^{2}\right)=11271.50$ \\
\hline
\end{tabular}

Berdasarkan Tabel 2 matriks ragam peragam sampel yang akan dibuat grafik 


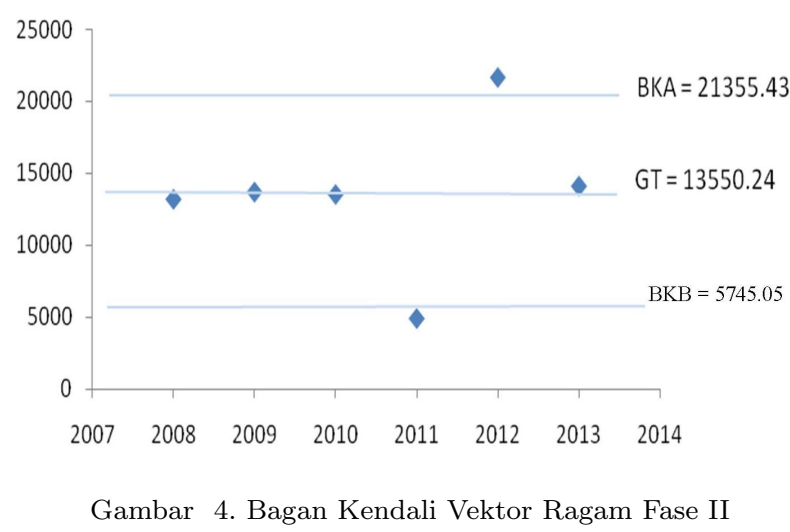

dengan menggunakan batas kendali pada fase I yang disertai dengan matriks ragam peragam sampel fase II sebagai monitoring atau pengontrol. Dari hasil tersebut, maka bagan kendali untuk fase II dapat dilihat pada Gambar 4.

Dari bagan kendali Gambar 4, terlihat bahwa pengamatan ke-4 dan ke5 merupakan titik out of control atau diluar batas kendali, dikarenakan oleh adanya suatu program khusus jurusan matematika dimana para mahasiswanya harus lulus dengan lama studi $\leq 4$ tahun, maka pengamatan ke-4 dengan 34 orang dihilangkan. Mahasiswa jumlah 34 orang adalah berasal dari proyek Basic Sains yang harus tamat 4 tahun. Langkah pembuatan bagan kendali seperti diatas diulangi lagi dengan jumlah sampel sebanyak 59 orang pada Tabel 3. Tabel 3. Matriks Ragam Sampel dan Ukuran Keragaman Tahun 2011-2013

\begin{tabular}{ccc}
\hline Tahun & Matriks Ragam Peragam Sampel & $\operatorname{Ts}\left(S^{2}\right)$ \\
\hline 2011 & {$\left[\begin{array}{cc}0.07 & -0.71 \\
-0.71 & 96.82\end{array}\right]$} & 9375.13 \\
2012 & {$\left[\begin{array}{cc}0.09 & -3.02 \\
-3.02 & 147.06\end{array}\right]$} & 21644.23 \\
2013 & {$\left[\begin{array}{cc}0.08 & -2.70 \\
-2.70 & 118.61\end{array}\right]$} & 14082.92 \\
\hline Rata-rata & {$\left[\begin{array}{cc}0.08 & -2.15 \\
-2.15 & 122.53\end{array}\right]$} & $\operatorname{Tr}\left(\bar{S}_{\text {gab. }}^{2}\right)=15022.85$ \\
\hline
\end{tabular}

Dari hasil tersebut, maka bagan kendali untuk fase II dapat dilihat pada Gambar 3.

Dari bagan kendali Gambar 5, terlihat bahwa pengamatan ke-4 pada tahun 2011 telah berada di dalam batas kendali. Pada pengamatan ke-5 tahun 2012 merupakan titik out of control atau diluar batas kendali. Sehingga beberapa mahasiswa sebagian kecil yang lulus lebih dari 4 tahun sehingga perlu adanya evaluasi bagi para lulusan tersebut dengan cara evaluasi yang dilakukan adalah pendataan pada mahasiswa yang lama studinya lebih dari 4 tahun serta mencari solusi/antisipasi agar mahasiswa tersebut tidak melewati batas lama studinya 


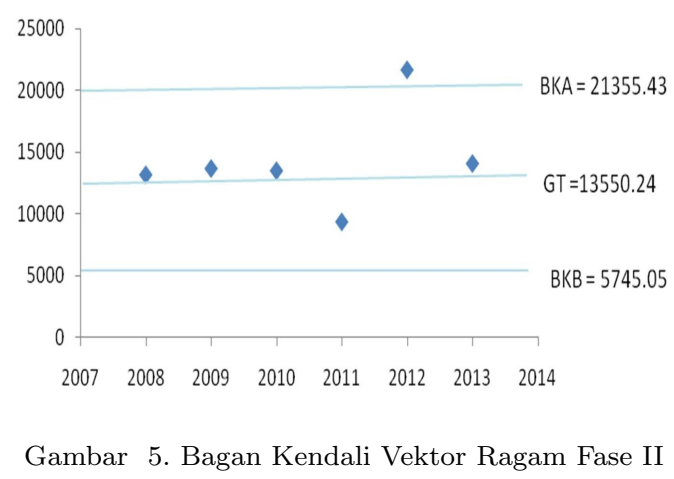

lebih dari 4 tahun terkhusus untuk Mahasiswa Jurusan Matematika Universitas Andalas.

\section{Penutup}

Dari bagan kendali vektor ragam fase data pendahuluan disimpulkan bahwa $\operatorname{Tr}\left(S^{2)}\right.$ dari matriks ragam peragam IPK dan lama studi lulusan Mahasiswa Matematika Universitas Andalas berada dalam batas kendali. Berdasarkan deskriptif data yang telah dijelaskan bahwa ada data yang memiliki sebaran yang tidak teratur. Data yang dimaksud adalah data lama studi lulusan. Berdasarkan interfretasi bahwa lama studi lulusan Mahasiswa Jurusan Matematika Universitas Andalas mempunyai pengaruh terhadap bagan kendali vektor ragam. Dengan demikian, dapat disimpulkan bahwa perlu adanya evaluasi serta solusi yang terbaik untuk lama studi bagi mahasiswa terutama mahasiswa matematika Universitas Andalas agar pada tahun berikutnya tidak ada lagi mahasiswa yang menyelesaikan studinya terlalu lama.

\section{Ucapan Terima kasih}

Penulis mengucapkan terima kasih kepada Bapak Dodi Devianto, Ibu Izzati Rahmi HG dan Bapak Yudiantri Asdi yang telah memberikan masukan dan saran sehingga makalah ini dapat diselesaikan dengan baik.

\section{Daftar Pustaka}

[1] Djauhari, Maman A. (2011). Geometric Interpretation of Vector Variance. Universiti Teknologi Malaysia. Jurnal Matematika, Volume 27, Number 1, 51-57.

[2] Johnson, R.A., D.W. Wichern. 1998. Applied Multivariate Statistical Analysis 4 th Edition. Prentice Hall, Inc., United States of America

[3] Montgomery, D.C. 2009. Introduction to Statistical Quality Control, Sixth Edition. John Wiley And Son, Inc., New York

[4] Sahabuddin, dkk. Pengendalian proses variabilitas multivariate melalui vektor variansi. Tesis. Universitas Hasanuddin, Makassar

[5] Walpole, R.E dan Raymond H. Myers. 1995. Ilmu Peluang dan Statistika untuk Insinyur dan Ilmuwan Edisi ke-4. ITB, Bandung. 